\title{
An App-Based Intervention for Adolescents Exposed to Cyberbullying in Norway: Protocol for a Randomized Controlled Trial
}

Sabine Kaiser ${ }^{1}, \mathrm{PhD}$; Monica Martinussen ${ }^{1}, \mathrm{PhD}$; Frode Adolfsen ${ }^{1}, \mathrm{PhD}$; Kyrre Breivik ${ }^{2}, \mathrm{PhD}$; Henriette Kyrrestad ${ }^{1}$, $\mathrm{PhD}$

${ }^{1}$ Regional Centre for Child and Youth Mental Health and Child Welfare - North, UiT The Arctic University of Norway, Troms $\varnothing$, Norway

${ }^{2}$ Regional Centre for Child and Youth Mental Health and Child Welfare - West, NORCE, Norwegian Research Center AS, Bergen, Norway

Corresponding Author:

Sabine Kaiser, $\mathrm{PhD}$

Regional Centre for Child and Youth Mental Health and Child Welfare - North

UiT The Arctic University of Norway

Campus Troms $\varnothing$, Breivika

Tromsø, 9019

Norway

Phone: 4777645850

Email: sabine.kaiser@uit.no

\section{Abstract}

Background: Adolescents exposed to negative online events are at high risk to develop mental health problems. Little is known about what is effective for treatment in this group. NettOpp is a new mobile app for adolescents who have been exposed to cyberbullying or negative online experiences in Norway.

Objective: The aim of this paper is to provide a description of the content of the intervention and about a randomized controlled trial that will be conducted to examine the effectiveness of NettOpp. This protocol is written in accordance with the Spirit 2013 Checklist.

Methods: An effectiveness study with a follow-up examination after 3 months will be conducted to evaluate the mobile app. Adolescents will be recruited through schools and will be randomly assigned to the intervention (NettOpp) group and a waiting-list control group. The adolescents (aged 11 to 16 years) will respond to self-report questionnaires on the internet. Primary outcomes will be changes in mental health assessed with the Strengths and Difficulties Questionnaire, the WHO-Five Well-being Index, and the Child and Adolescent Trauma Screen.

Results: Recruitment will start in January 2022. The results from this study will be available in 2023.

Conclusions: There are few published evaluation studies on app-based interventions. This project and its publications will contribute new knowledge to the field.

Trial Registration: ClinicalTrials.gov NCT04176666; https://clinicaltrials.gov/ct2/show/NCT04176666

International Registered Report Identifier (IRRID): PRR1-10.2196/31789

(JMIR Res Protoc 2021;10(11):e31789) doi: 10.2196/31789

\section{KEYWORDS}

cyberbullying; intervention; mobile app; adolescents; NettOpp; mental health; adolescents; health care

\section{Introduction}

\section{Background}

The technological revolution has led to most young people being able to now use the internet and mobile phones daily to communicate with others, socialize, entertain themselves, and find information. This development goes hand in hand with many new challenges and possibilities also when it comes to aversive behavior among children and youth. On the one hand, cyberbullying and other negative online experiences affect many children and youth. On the other hand, this technological development opens up for new innovative technologies to help and support young people exposed to such behavior. 
Cyberbullying can be defined as an "aggressive, intentional act carried out by a group or individual, using electronic forms of contact, repeatedly and over time against a victim who cannot easily defend him or herself" [1]. Electronic forms can be the internet and other digital technologies including mobile phones that are used to, for example, call, write emails, instant, and text messages, chats, blogs, or web posts to say mean things, insult, threaten, or make fun of somebody, to spread rumors, lies, embarrassing information, or pictures [2]. Cyberbullying can take on many different forms, from passively ignoring or excluding somebody from a group to more active actions such as sending or posting cruel or embarrassing messages about someone $[2,3]$.

Cyberbullying prevalence rates among 12-to-18-year-old individuals vary from $5 \%$ to $74 \%$ with a median of $23 \%$, as reported in a review by Hamm et al [4]. Some of this variation can probably be explained by age group and country differences in the prevalence of cyberbullying. Nonetheless, we believe it is likely that this huge variation is also due to the use of different definitions, perceptions, and interpretation for cyberbullying across studies; that is, does cyberbullying have to occur repeatedly or is one occurrence enough [3-6] and what are the different types of scales used to measure the phenomenon? The annual conducted Norwegian school survey among 10-to-18-year-old students reported a cyberbullying rate of $2 \%$ in 2017 with a peak (2.6\%) in junior high school [7]. This is the proportion of adolescents who report that they have been cyberbullied 2-3 times a month or more. The proportion increases to $10 \%$ if adolescents who have experienced one negative online event are included.

The consequences of bullying victimization in adolescence are serious. Meta-analyses have found that bullying, both traditionally and on the internet, is related to mental health problems such as depression, anxiety, and poor general health $[8,9]$. Furthermore, there is an association between bullying victimization and psychosomatic health complaints such as stomach ache, sleeping difficulties, and headache and social functioning including social isolation, loneliness, and low self-esteem $[2,8,10]$.

Given the seriousness of bullying or cyberbullying victimization, interventions that aim at preventing cyberbullying and helping and supporting those exposed to cyberbullying are important. A recently published meta-analysis found that intervention and prevention programs for cyberbullying can reduce cyberbullying victimization [11]. Furthermore, some traditional antibullying programs have also proven to have an effect on cyberbullying $[12,13]$.

A review found that there are more preventive antibullying programs compared to interventions for adolescents who have been exposed to cyberbullying [10]. However, such studies suggest that cognitive measures appear to be effective [10]. A systematic review of digital bullying from the Norwegian Institute of Public Health did not identify any available interventions in Norway, except for 2 anticyberbullying campaigns [14]. Those campaigns were neither theoretically grounded nor evaluated. The report encourages using technology and being innovative when developing measures to prevent cyberbullying [14] as adolescents spend a lot of their time on the internet and with their mobile phones [15]. Furthermore, many adolescents find it difficult to tell their parents or other adults about their experiences of being bullied or cyberbullied $[16,17]$. Therefore, a mobile app may be a useful resource as they are always accessible, easy to use, and they offer anonymity.

Several health-promoting apps aimed at youth have been developed. Many of them aim to promote health by monitoring or motivating the user to adopt healthier diets or increase their physical activity [18]. Other apps are more supportive in which the purpose is to learn how to cope with, for example, chronic diseases such as diabetes, asthma, or cancer [19]. Overall, two reviews concluded that apps may have the potential to be feasible health interventions for young people, but that more studies are needed to assess their effectiveness [19,20]. In addition to this, Shieh (2016) has found 9 anticyberbullying apps with different focus [21]. However, none of these apps have been empirically evaluated or adapted to Norwegian conditions, indicating the need for the development and evaluation of an app against cyberbullying in Norway.

\section{The Cyberbullying Coping Intervention}

NettOpp is a mobile app for adolescents who have been exposed to cyberbullying or other negative online experiences in Norway (Figure 1). NettOpp directly translated means "exactly" in English but "Nett" refers also to the internet and "Opp" comes from "Opplysning," which means information or enlightenment. The target group of the cyberbullying coping intervention was adolescents in elementary school and junior high school, between 11 to 16 years of age. According to Jacobs et al [22] (2014), a cyberbullying coping intervention should do more than just increase awareness about internet threats. Ideally, an intervention should reduce the risks for getting victimized, combat cyberbullying once it occurred, and buffer the negative impact of the event [23].

The primary aim of this intervention is (1) to reduce mental health problems related to cyberbullying; the secondary aims are to (2) increase adolescents coping skills with cyberbullying, (3) increase knowledge about cyberbullying, (4) increase the help-seeking behavior of the adolescents, (5) increase their self-esteem, (6) increase their sleeping quality, and finally, (7) reduce cyberbullying. Below a description of why it is important to focus on the aforementioned aims. 
Figure 1. NettOpp start page.

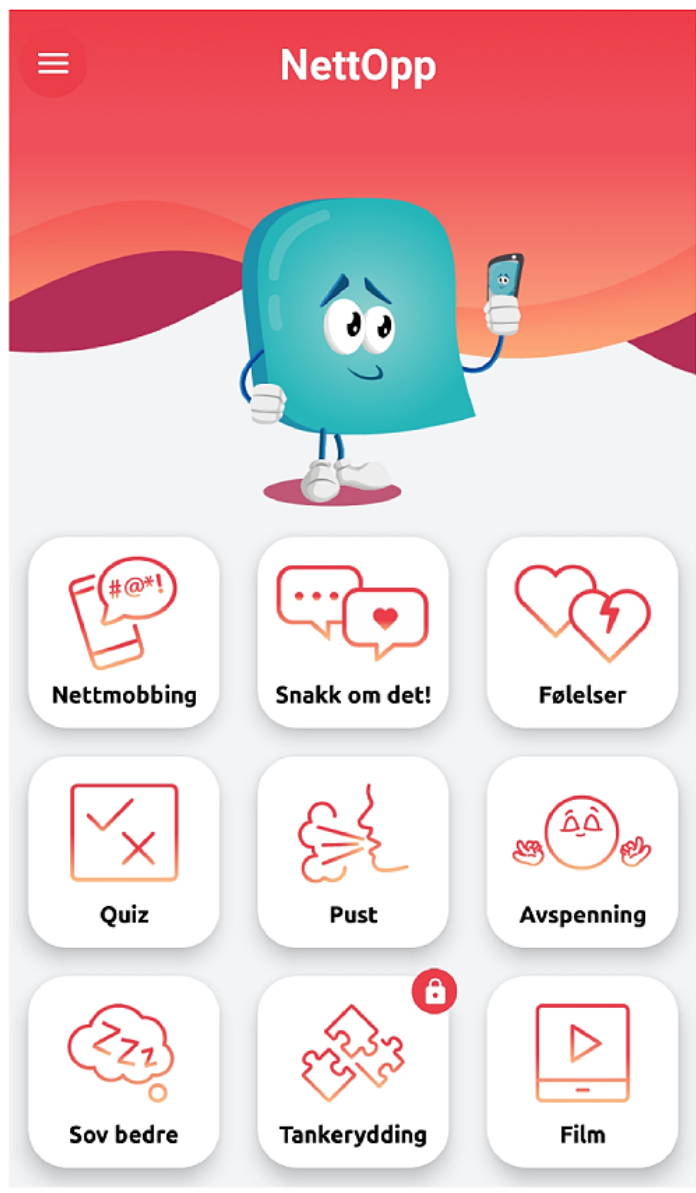

A previously conducted user survey $(\mathrm{N}=15)$ showed that most users found NettOpp easy to use, appealing, and would recommend the mobile app to a friend. A total of 14 out of 15 adolescents agreed that NettOpp would probably increase knowledge about cyberbullying and 5 out of 15 believed that NettOpp would reduce cyberbullying [24].

\section{Reduce Mental Health Problems}

Adolescents exposed to cyberbullying are at high risk for developing mental health problems. The intensity and duration of the cyberbullying may determine how serious the consequences are [25]. Giving the adolescents advice on how to cope with cyberbullying might have a buffering impact and can reduce mental health problems. A study found that, for example, help-seeking behavior buffered the negative impact of cyber victimization on depressive symptoms [26] and internalizing problems [27]. In addition, learning how to deal with a cyberbullying event may shorten the cyberbullying episode and thereby prevent serious consequences that could affect the health of the adolescents.

\section{Increase Adolescents' Coping Skills With Cyberbullying}

How an adolescent copes with a cyberbullying event can determine whether he/she experiences long-term consequences [22]. A study found that among the most helpful coping strategies to stop cyberbullying were technical strategies (eg, blocking or deleting the person or profile), help-seeking behavior, and behavioral avoidance (eg, stopping visiting the webpages where the event happened) [28].

Furthermore, cyberbullying is emotionally distressing and young people exposed to it can feel upset, hurt, embarrassed, helpless, isolated, and scared for their safety [29]. Teaching adolescents about normal emotional reactions to a cyberbullying event and how to cope with the feelings could be emotionally helpful. Healthy coping strategies (eg, help-seeking and talking about the problem or using relaxation techniques, listening to music, or thinking positive thoughts) could replace unhealthy coping strategies (eg, social withdrawal, self-harm, aggression, or skipping school), and buffer the negative impact of the cyberbullying event [23]. A study found that among the most emotionally helpful coping strategies for cyberbullying victims were support-seeking, technical strategies, behavioral avoidance, and reframing the situation (eg, "whoever is doing this to me is not worth my time") [28].

\section{Increase Knowledge About Cyberbullying}

Increasing knowledge about what cyberbullying is, what consequences are associated with it, rights and laws, security advice, and what can be done in the case of a cyberbullying event is an important part of the psychoeducation adolescents should receive [25,30]. It will increase awareness of the problem, its seriousness, and help the adolescent to act safer on the internet and thus reduce the risk of being victimized in the future. Providing information on how to deal with an event 
might help the adolescent to combat cyberbullying once it occurred.

\section{Increase Help-Seeking Behavior Among Adolescents}

Some studies that examined help-seeking behavior among individuals exposed to traditional bullying have found that telling an adult made things worse for some adolescents [27,31,32]. Regarding cyberbullying, Price and Dalgleish [33] found that the majority (approximately 60\%-70\%) of adolescents who sought help found this helpful to some degree. For the remaining individuals, help-seeking did not change the situation. Price and Dalgleish [33] concluded, "a critical response to effectively addressing cyberbullying relies on both increasing the help-seeking behaviour of victimized young people and improving the efficacy of those they speak to." Seeking support was also found to be emotionally helpful for the majority of victims of cyberbullying and helped to stop cyberbullying for some adolescents in another study [28]. However, some adolescents do not have a trusted adult around, or they are too ashamed or afraid to tell somebody they know and may prefer to contact someone anonymously [23]. Encouraging adolescents to seek help, provide information about whom to contact (eg, also about online resources and helplines), how to seek help, and what should happen when adolescents have sought help at school are important [22].

\section{Increase the Self-esteem of the Adolescents}

Low self-esteem in adolescence has been found to predict negative consequences such as poor physical and mental health during adulthood [34]. Studies have found a negative relationship between cyberbullying victimization and self-esteem [35-37]. Interventions that aim to increase self-esteem are therefore important. Most of the studies that aim at increasing self-esteem use physical exercise as the intervention [38].

\section{Increase the Sleeping Quality}

Insufficient sleep among adolescents is related to physiological and mental health risks such as cardiometabolic dysfunction, poor academic performance, or mood disturbances such as increased suicidal ideation [39], and it was found to be a precursor to depression [40]. A meta-analysis found that peer victimization like bullying among children and adolescents was related to sleeping problems [41]. Healthy lifestyles including longer sleep duration, on the other hand, was associated with less suicidal ideation among individuals exposed to cyberbullying [42]. In general, a review and meta-analysis found that cognitive-behavioral sleep interventions for adolescents are effective in improving sleeping quality [43].

\section{Reduce Cyberbullying}

Cyberbullying rates can be reduced by increasing the knowledge and skills about how to handle cyberbullying [25]. The knowledge adolescents will acquire about what cyberbullying is, what consequences are associated with it, and rights and laws may lead to increased awareness of the problem. By teaching the adolescents how to reduce risks of being victimized and how to better cope with a cyberbullying event might help to stop cyberbullying and prevent new occurrences and thus reduce cyberbullying rates.

\section{The Mobile App}

The app will consist of 2 modules. Module 1 will be psychoeducational including information about cyberbullying, its consequences, rights and laws, practical and technical advice about how to cope with a cyberbullying event (eg, blocking or deleting a person). This will hopefully increase adolescents' knowledge about cyberbullying. The app will also provide tips about what the adolescents can do to reduce new occurrences of cyberbullying events (eg, 'Don't add 'Friends' that you don't know who is," "Be critical of which images you share with others," and "Check your privacy settings on social media"). In addition, the adolescents will learn about normal emotional reactions when exposed to cyberbullying (eg, fear, helplessness, shame, and sadness) and how to cope with them. This will contribute to increased coping skills with cyberbullying. Further, the psychoeducational information focuses on motivating adolescents to seek help from a trusted adult. Adolescents are advised to contact a trusted adult who they think can help in case of cyberbullying or a negative online experience. The app further informs about how one can talk about difficult things to someone else and about what should happen once the adolescent has told an adult. In addition, there is information about available professional online resources including chats and helplines the adolescents can contact in case they do not know with whom to talk or prefer to stay anonymous. This might increase help-seeking behavior among adolescents.

Module 2 will be a resource module that provides exercises and techniques on how to cope with emotional distress related to cyberbullying. These exercises include relaxation techniques (breathing and guided meditation exercises) that aim at increasing the adolescents' coping skills with the cyberbullying event. The exercises also include sleep hygiene-related advice and exercises to increase the sleep quality of adolescents that have, for example, difficulties to fall asleep because of worries. The adolescents will be encouraged to create a bedroom where they feel safe, enjoy themselves, and relax. They will also be encouraged to relate to their concerns and quarry thoughts during daytime.

The app also includes an exercise based on cognitive behavioral therapy, which aims at helping the adolescents to reframe the situation [44]. The aim is to make the adolescents aware of the connection between thoughts and feelings, and at increasing awareness about negative thoughts the adolescents might have because of the cyberbullying event and replacing these thoughts with alternative thoughts. The adolescents will be guided through this exercise by giving them the opportunity to choose between different statements. First, they can choose a statement that fits best to their situation (eg, "Someone has posted a picture or video of me that I don't like"). Then, they can identify the negative thoughts (eg, "I'm thick/ugly/stupid" and "Everyone is going to think I look stupid") and rate how strongly they believe in this thought on a scale from 0 to 10 . In a third step, they can identify the negative feelings they are experiencing (eg, "I feel sad and tired" and "I'm ashamed") and rate how strongly they experience this feeling on a scale from 0 to 10 . Thereafter, they will be shown a list of alternative thoughts. They will be instructed to pick out alternative thoughts or advice on what they could do, what they can say to themselves, and 
what they would have said to a friend who was in a similar situation. They can select up to 3 statements (eg, "It's not my fault that I'm being exposed to this," "I can ask for help [e.g., from parents, teachers, health nurses]," and "There are many people that like and care about me"). In a last step, the adolescents can rate how strong the original, negative thought and the feelings are and rate once more if they feel better, the same, or worse. The overall aim of this and the other exercises is to increase coping skills with a cyberbullying event and thus to prevent the development of mental health problems.

Furthermore, every second day, the adolescents will receive a push-message in the app, which will either say something nice (eg, "Do something nice for yourself") or motivate the adolescents to do an exercise (eg, "Relax and do a breathing exercise").

Information will be displayed in the app through text, sound recordings, and short movies, to keep the adolescents engaged with the app. In addition, rights and laws associated with cyberbullying will be communicated to the adolescents through quizzes.

\section{User Involvement}

The users, in our case Norwegian elementary and junior high school students, have been involved in the project from the development of the intervention to its evaluation. The app was developed in collaboration with the users in terms of what the intervention should contain, but also in terms of functionality and format of the app. The 8 adolescents in the user group were involved through workshops. A larger reference group consisted of teachers, school health nurses, nurses from the health care station for adolescents, community psychologists, and the local antibullying professional.

The aim of the current paper is to provide a description of the content of the intervention and the randomized controlled trial that will be conducted to examine the effectiveness of NettOpp.

\section{Methods}

\section{Eligibility Criteria and Setting of the Effectiveness Study}

Adolescents from the 6th to 10th grade (11-16 years old) are eligible for participation in the effectiveness study. Adolescents will be recruited through schools in Norway. To recruit enough participants, the schools need to be big enough; that is, they should have at least 20 students in each class.

\section{Inclusion and Exclusion Criteria}

Adolescents between the ages of 11 and 16 years, whose guardians have given consent and who agree to take part in the study, will be included. To use the app, adolescents need a smartphone and be able to read and understand Norwegian. Furthermore, android users must provide a Gmail address, and iPhone users must first download the free app TestFlight to be able to download a test version of NettOpp. Adolescents who may not benefit from an app-based intervention because of, for example, severe developmental or cognitive challenges will be excluded from the study.

\section{Intervention}

NettOpp is a self-help tool that aims at supporting adolescents who have been exposed to cyberbullying or a negative online event. Adolescents can install the app on their mobile phone and use it as much as they want and whenever they want. The intervention focuses on psychoeducation, on motivating the adolescents to seek help from a trusted adult, and on strategies to better cope with stress related to cyberbullying or negative online experiences.

\section{Control}

The waiting-list control group will receive access to the app after study completion; that is, when the follow-up assessment is conducted after approximately 3 months.

\section{Randomization}

The effectiveness study will be conducted as a randomized controlled trial with an intervention group and a waiting-list control group. Randomization will be conducted after baseline measures have been collected at the school level by a statistician. A random number between 0 and 1 will be generated using SPSS and assigned to each school. Half of the schools with the highest value on the random variable will be assigned to the intervention group and half of the schools with the lowest value will be assigned to the waiting-list control group.

\section{Blinding}

Adolescents are randomized to the intervention or waiting-list control group and are blinded to the allocation prior to the baseline assessment, and their schools will also not receive information about their allocation. The information letters include information about study content and purpose, but guardians and students were both blinded to the allocation to the intervention or waiting-list control group prior to offering their consent or before the baseline assessment.

\section{Outcomes}

Data will be collected at baseline $\left(\mathrm{T}_{1}\right.$, preintervention) and after approximately 2 weeks of the intervention ( $\mathrm{T}_{2}$, postintervention) through self-report measures that the adolescents fill in using Nettskjema, a secure online tool to conduct surveys [45]. A follow-up evaluation $\left(\mathrm{T}_{3}\right)$ will be conducted after approximately 3 months to examine if the effects were stable over time.

\section{Primary Outcomes}

Mental health will be assessed with the Strengths and Difficulties Questionnaire (SDQ) [46], the WHO-Five Well-being Index (WHO-5) [47], and the Child and Adolescent Trauma Screen (CATS) [48]. The null hypothesis of this study is that there will not be significant differences in changes in mental health scores between the waiting-list control and the intervention group.

\section{Secondary Outcomes}

How the adolescents cope with cyberbullying will be measured with the Cyberbullying Coping Questionnaire [49]. Help-seeking behavior will be assessed with 3 questions; for example, "Have you told someone about your experiences so they can help you?" Health problems will be assessed using 7 items asking the 
respondent how often he/she has, for example, experienced headaches. Self-esteem will be measured with the Norwegian Version of the Self-liking and Competence Scale [50,51]. Sleeping quality will be measured with 6 questions (eg, "At what time do you usually go to bed?") from the Bergen Child Study [52]. Cyberbullying and bullying experiences will be assessed using 4 questions based on the Olweus questionnaire [5].

\section{Power Calculations}

Power calculations were conducted using the software PASS 16 [53]. Using multilevel analysis, it will require a total sample of 400 participants (200 in each group: 20 schools with 20 students per group) to detect an effect size of at least Cohen $d=0.30$, when the expected interclass correlation at school level is 0.01 , with a power of 0.79 , and a significance level of .05 .

\section{Data Management}

Data collection, data cleaning, and statistical analyses will be performed by members of the research team. The statistical analyses will be conducted on anonymized data and only members of the research team will have access to the data. Data will be stored on a secure server.

\section{Planned Statistical Analysis}

A linear mixed model will be used for analyzing the outcomes in the effectiveness study. Missing data will be handled using multiple imputation.

\section{Ethics Approval and Consent to Participate}

The effectiveness study is approved by the regional Research Ethics Committee (reference number 161212). The studies are approved by the Norwegian Centre for Research Data (NSD) (reference number 545417). Since the study participants are between 11 to 16 years old, study participation requires consent from an authorized guardian. The consent form and information letter to the guardians and study participants are approved by the regional Research Ethics Committee and by the NSD. Changes to the project, which may impact study participants will be reported to the regional Research Ethics Committee and to the NSD.

\section{Results}

The study has been approved by the regional Research Ethics Committee and by the NSD. The mobile app NettOpp has been developed, and enrollment for the study will begin in January 2022. The results of the study will be published in 2023 .

\section{Discussion}

\section{Expected Outcomes}

Adolescents who have been exposed to cyberbullying are vulnerable to mental health problems and other harmful effects of the stressful events. In addition to the negative effects that cyberbullying can have for those who have been exposed to it, there may be a considerable financial burden to the society, which is associated with the consequences of mental health problems in adolescence and over the lifespan $[8,54,55]$. The threshold for telling and seeking help from a trusted adult might be too high and as such, there is a need for a low-threshold intervention against cyberbullying for adolescents.

NettOpp is a mobile app for adolescents who have been exposed to cyberbullying or a negative online experience in Norway. Its evaluation will contribute unique knowledge to the field as there are very few interventions targeting adolescents who have been exposed to cyberbullying. The aim of this paper is to provide a description of the content of the intervention and about its evaluation. The results of the evaluation will be presented in other studies. If the intervention is found to be effective, it will be free of charge and available to all adolescents in Norway.

\section{Challenges}

The intervention and its evaluation have several limitations. First, the intervention may be too comprehensive, aim at too many areas (ie, knowledge, coping, self-esteem, sleep, mental health, and reduce cyberbullying rates), and may partly contain too much information. In particular, the exercise where the adolescent learns about unhelpful or inappropriate thoughts and reframing the situation is long and is based on written information. This might not be appealing to adolescents and that they will therefore not use it. However, it is difficult to redesign this exercise to make it more attractive. Furthermore, we find that the exercise is too important to exclude it from the intervention. The questionnaire to evaluate the intervention is long and may lead to dropping out, response fatigue, or saying no or yes [22]. However, it is necessary to assess these measures to evaluate the effectiveness of the intervention. Both working with the intervention and filling in the questionnaire can be potentially distressing for the adolescents as they are confronted with the seriousness of the cyberbullying event and their thoughts, feelings, and consequences of the event. Therefore, we inform the adolescents about possible contact persons such as school nurses and provide a number to a helpline in the information letter and in the online questionnaire. However, in general, we expect the benefits of the intervention to exceed its disadvantages.

\section{Acknowledgments}

The publication charges for this article have been sponsored by a grant from the publication fund of the Arctic University of Norway (UiT). The study is funded by the Norwegian Directorate of Health and the UiT. The funding organizations are not involved in the design of the study or in the collection, analysis, and interpretation of data or in writing the manuscript.

\section{Authors' Contributions}

All authors provided substantial contributions to the intervention and the study protocol. SK wrote the first draft of the manuscript. HK is the principal investigator of the study. MM, FA, KB, and HK read, edited, and approved the final manuscript. 


\section{Conflicts of Interest}

None declared.

\section{References}

1. Smith PK, Mahdavi J, Carvalho M, Fisher S, Russell S, Tippett N. Cyberbullying: its nature and impact in secondary school pupils. J Child Psychol Psychiatry 2008 Apr;49(4):376-385. [doi: 10.1111/j.1469-7610.2007.01846.x] [Medline: 18363945]

2. Kowalski RM, Giumetti GW, Schroeder AN, Lattanner MR. Bullying in the digital age: a critical review and meta-analysis of cyberbullying research among youth. Psychol Bull 2014 Jul;140(4):1073-1137. [doi: 10.1037/a0035618] [Medline: 24512111]

3. Smith PK. The nature of cyberbullying and what we can do about it. J Res Spec Educ Needs 2015 Jul 14;15(3):176-184. [doi: $10.1111 / 1471-3802.12114]$

4. Hamm MP, Newton AS, Chisholm A, Shulhan J, Milne A, Sundar P, et al. Prevalence and Effect of Cyberbullying on Children and Young People: A Scoping Review of Social Media Studies. JAMA Pediatr 2015 Aug;169(8):770-777. [doi: 10.1001/jamapediatrics.2015.0944] [Medline: 26098362]

5. Olweus D. Bullying at School: What We Know and What We Can Do. Hoboken, NJ: Wiley; 1993:1-152.

6. Hellevik P, Øverlien C. Digital mobbing blant barn og ungdom i Norge - En kunnskapsoversikt 2013. Oslo: Nasjonalt kunnskapssenter om vold og traumatisk stress. 2013. URL: https://www.nkvts.no/rapport/

digital-mobbing-blant-barn-og-ungdom-i-norge-en-kunnskapsoversikt-2013/ [accessed 2021-10-15]

7. Wendelborg C. Mobbing og arbeidsro i skolen Analyse av Elevundersøkelsen skoleåret 2017/18. Trondheim: NTNU Samfunnsforskning AS; 2018:1-34.

8. Moore SE, Norman RE, Suetani S, Thomas HJ, Sly PD, Scott JG. Consequences of bullying victimization in childhood and adolescence: A systematic review and meta-analysis. World J Psychiatry 2017 Mar 22;7(1):60-76 [REE Full text] [doi: 10.5498/wjp.v7.i1.60] [Medline: 28401049]

9. Gini G, Card NA, Pozzoli T. A meta-analysis of the differential relations of traditional and cyber-victimization with internalizing problems. Aggress Behav 2018 Mar;44(2):185-198. [doi: 10.1002/ab.21742] [Medline: 29160943]

10. Breivik K, Bru E, Hancock C, Idsøe E, Idsøe T, Solberg M. A bli utsatt for mobbing - en kunnskapsoppsummering om konsekvenser og tiltak. 2017. URL: https://www.udir.no/tall-og-forskning/finn-forskning/rapporter/ a-bli-utsatt-for-mobbing--en-kunnskapsoppsummering-om-konsekvenser-og-tiltak/ [accessed 2021-10-15]

11. Gaffney H, Farrington DP, Espelage DL, Ttofi MM. Are cyberbullying intervention and prevention programs effective? A systematic and meta-analytical review. Aggress Violent Behav 2019 Mar;45:134-153. [doi: 10.1016/j.avb.2018.07.002]

12. Olweus D, Limber SP, Breivik K. Addressing Specific Forms of Bullying: A Large-Scale Evaluation of the Olweus Bullying Prevention Program. Int J Bullying Prev 2019 Mar 11;1(1):70-84. [doi: 10.1007/s42380-019-00009-7]

13. Williford A, Elledge LC, Boulton AJ, DePaolis KJ, Little TD, Salmivalli C. Effects of the KiVa antibullying program on cyberbullying and cybervictimization frequency among Finnish youth. J Clin Child Adolesc Psychol 2013;42(6):820-833. [doi: 10.1080/15374416.2013.787623] [Medline: 23659182]

14. Ulriksen R, Knapstad M. Digital mobbing-Kunnskapsoversikt over forskning på effekter av tiltak. Norwegian Institute of Public Health, Norway. 2016. URL: https://www.fhi.no/publ/2016/ digital-mobbing.-kunnskapsoversikt-over-forskning-pa-effekter-av-tiltak/ [accessed 2021-10-15]

15. Norwegian MA. Barn \& medier 2016 - 9-16 åringer bruk og opplevelser av medier. URL: https://docplayer.me/ 19307521-Barn-medier-2016-9-16-aringers-bruk-og-opplevelser-av-medier.html [accessed 2021-10-15]

16. Dooley JJ, Gradinger P, Strohmeier D, Cross D, Spiel C. Cyber-Victimisation: The Association Between Help-Seeking Behaviours and Self-Reported Emotional Symptoms in Australia and Austria. J Psychol Couns Sch 2012 Feb 23;20(2):194-209. [doi: 10.1375/ajgc.20.2.194]

17. Scott E, Dale J, Russell R, Wolke D. Young people who are being bullied - do they want general practice support? BMC Fam Pract 2016 Aug 22;17(1):116 [FREE Full text] [doi: 10.1186/s12875-016-0517-9] [Medline: 27550153]

18. Schoffman DE, Turner-McGrievy G, Jones SJ, Wilcox S. Mobile apps for pediatric obesity prevention and treatment, healthy eating, and physical activity promotion: just fun and games? Transl Behav Med 2013 Sep;3(3):320-325 [FREE Full text] [doi: 10.1007/s13142-013-0206-3] [Medline: 24073184]

19. Majeed-Ariss R, Baildam E, Campbell M, Chieng A, Fallon D, Hall A, et al. Apps and Adolescents: A Systematic Review of Adolescents' Use of Mobile Phone and Tablet Apps That Support Personal Management of Their Chronic or Long-Term Physical Conditions. J Med Internet Res 2015 Dec 23;17(12):e287 [FREE Full text] [doi: 10.2196/jmir.5043] [Medline: 26701961]

20. Punukollu M, Marques M. Use of mobile apps and technologies in child and adolescent mental health: a systematic review. Evid Based Ment Health 2019 Nov;22(4):161-166. [doi: 10.1136/ebmental-2019-300093] [Medline: 31358537]

21. Shieh B. CyberPAL: a mobile resource for cyberbullying. Pepperdine University. 2016. URL: https://digitalcommons. pepperdine.edu/cgi/viewcontent.cgi?article=1621\&context=etd [accessed 2021-10-15] 
22. Jacobs NC, Völlink T, Dehue F, Lechner L. Online Pestkoppenstoppen: systematic and theory-based development of a web-based tailored intervention for adolescent cyberbully victims to combat and prevent cyberbullying. BMC Public Health 2014 Apr 24;14:396 [FREE Full text] [doi: 10.1186/1471-2458-14-396] [Medline: 24758264]

23. Perren S, Corcoran L, Cowie H, Dehue F, Garcia D, Mc Guckin C, et al. Tackling Cyberbullying: Review of Empirical Evidence Regarding Successful Responses by Students, Parents, and Schools. Int J Confl Violence 2012;6(2):283-292 [FREE Full text]

24. Kaiser S, Martinussen M, Breivik K, Adolfsen F, Kyrrestad H. En brukerundersøkelse av mobilappenNettOpp. In: A user survey of the mobile appNettOpp. 2020 Dec 02 Presented at: Barn og Unge Kongressen; December 2, 2020 ; Bergen p. 1.

25. Wölfer R, Schultze-Krumbholz A, Zagorscak P, Jäkel A, Göbel K, Scheithauer H. Prevention 2.0: targeting cyberbullying @ school. Prev Sci 2014 Dec;15(6):879-887. [doi: 10.1007/s11121-013-0438-y] [Medline: 24122481]

26. Machmutow K, Perren S, Sticca F, Alsaker FD. Peer victimisation and depressive symptoms: can specific coping strategies buffer the negative impact of cybervictimisation? Emotional and Behavioural Difficulties 2012 Sep;17(3-4):403-420. [doi: 10.1080/13632752.2012.704310]

27. Shaw T, Campbell MA, Eastham J, Runions KC, Salmivalli C, Cross D. Telling an Adult at School about Bullying: Subsequent Victimization and Internalizing Problems. J Child Fam Stud 2019 Jul 19;28(9):2594-2605. [doi: 10.1007/s10826-019-01507-4]

28. Machackova H, Cerna A, Sevcikova A, Dedkova L, Daneback K. Effectiveness of coping strategies for victims of cyberbullying. Cyberpsychology 2013 Dec 01;7(3). [doi: 10.5817/cp2013-3-5]

29. Nixon C. Current perspectives: the impact of cyberbullying on adolescent health. Adolesc Health Med Ther 2014;5:143-158 [FREE Full text] [doi: 10.2147/AHMT.S36456] [Medline: 25177157]

30. Camelford KG, Ebrahim C. The Cyberbullying Virus: A Psychoeducational Intervention to Define and Discuss Cyberbullying Among High School Females. J Creat Ment Health 2016 Dec 09;11(3-4):458-468. [doi: 10.1080/15401383.2016.1183545]

31. Mendez JJ, Bauman S, Sulkowski ML, Davis S, Nixon C. Racially-focused peer victimization: Prevalence, psychosocial impacts, and the influence of coping strategies. Psychol Violence 2016;6(1):103-111. [doi: 10.1037/a0038161]

32. Smith PK, Shu S. What Good Schools can Do About Bullying. Childhood 2016 Jul 24;7(2):193-212. [doi: 10.1177/0907568200007002005]

33. Price M, Dalgleish J. Cyberbullying-Experiences, impacts and coping strategies as described by Australian young people. Youth Stud Aust 2010;29(2):51-59.

34. Trzesniewski KH, Donnellan MB, Moffitt TE, Robins RW, Poulton R, Caspi A. Low self-esteem during adolescence predicts poor health, criminal behavior, and limited economic prospects during adulthood. Dev Psychol 2006 Mar;42(2):381-390. [doi: 10.1037/0012-1649.42.2.381] [Medline: 16569175]

35. Brewer G, Kerslake J. Cyberbullying, self-esteem, empathy and loneliness. Comput Hum Behav 2015 Jul;48:255-260. [doi: 10.1016/j.chb.2015.01.073]

36. Cénat JM, Hébert M, Blais M, Lavoie F, Guerrier M, Derivois D. Cyberbullying, psychological distress and self-esteem among youth in Quebec schools. J Affect Disord 2014 Dec;169:7-9 [FREE Full text] [doi: 10.1016/j.jad.2014.07.019] [Medline: 25128859]

37. Patchin J, Hinduja S. Cyberbullying and self-esteem. J Sch Health 2010 Dec;80(12):614-21; quiz 622-4. [doi: 10.1111/j.1746-1561.2010.00548.x] [Medline: 21087257]

38. Liu M, Wu L, Ming Q. How Does Physical Activity Intervention Improve Self-Esteem and Self-Concept in Children and Adolescents? Evidence from a Meta-Analysis. PLoS One 2015;10(8):e0134804 [FREE Full text] [doi:

10.1371/journal.pone.0134804] [Medline: 26241879]

39. Owens JA, Weiss MR. Insufficient sleep in adolescents: causes and consequences. Minerva Pediatr 2017 Aug;69(4):326-336. [doi: 10.23736/S0026-4946.17.04914-3] [Medline: 28211649]

40. Lovato N, Gradisar M. A meta-analysis and model of the relationship between sleep and depression in adolescents: recommendations for future research and clinical practice. Sleep Med Rev 2014 Dec;18(6):521-529. [doi: 10.1016/j.smrv.2014.03.006] [Medline: 24857255]

41. van Geel M, Goemans A, Vedder PH. The relation between peer victimization and sleeping problems: A meta-analysis. Sleep Med Rev 2016 Jun;27:89-95. [doi: 10.1016/j.smrv.2015.05.004] [Medline: 26140869]

42. Rodelli M, De Bourdeaudhuij I, Dumon E, Portzky G, DeSmet A. Which healthy lifestyle factors are associated with a lower risk of suicidal ideation among adolescents faced with cyberbullying? Prev Med 2018 Aug;113:32-40. [doi: 10.1016/j.ypmed.2018.05.002] [Medline: 29729287]

43. Blake MJ, Sheeber LB, Youssef GJ, Raniti MB, Allen NB. Systematic Review and Meta-analysis of Adolescent Cognitive-Behavioral Sleep Interventions. Clin Child Fam Psychol Rev 2017 Sep;20(3):227-249. [doi: 10.1007/s10567-017-0234-5] [Medline: 28331991]

44. Ariso J, Reyero D. Reconsidering the Scenario of Cyberbullying: Promoting the Internalization of the Locus of Control in Adolescents through Cognitive Restructuring. APS 2014 Jul 31;4(2):98-103. [doi: 10.2174/2210676604666140425112047]

45. Nettskjema. Universitetet i Oslo. URL: https://www.uio.no/tjenester/it/adm-app/nettskjema/ [accessed 2021-10-15]

46. Goodman R. The Strengths and Difficulties Questionnaire: a research note. J Child Psychol Psychiatry 1997 Jul;38(5):581-586. [doi: 10.1111/j.1469-7610.1997.tb01545.x] [Medline: 9255702] 
47. WHO. Wellbeing Measures in Primary Health Care/The Depcare Project. World Health Organization Regional Office for Europe. 1998. URL: https://www.euro.who.int/ data/assets/pdf file/0016/130750/E60246.pdf [accessed 2021-10-15]

48. Sachser C, Berliner L, Holt T, Jensen TK, Jungbluth N, Risch E, et al. International development and psychometric properties of the Child and Adolescent Trauma Screen (CATS). J Affect Disord 2017 Mar 01;210:189-195. [doi: 10.1016/j.jad.2016.12.040] [Medline: 28049104]

49. Jacobs N, Völlink T, Dehue F, Lechner L. The Development of a Self-Report Questionnaire on Coping with Cyberbullying: The Cyberbullying Coping Questionnaire. Societies 2015 May 18;5(2):460-491. [doi: 10.3390/soc5020460]

50. Silvera DH, Neilands T, Perry JA. A Norwegian translation of the self-liking and competence scale. Scand J Psychol 2001 Dec;42(5):417-427. [doi: 10.1111/1467-9450.00254] [Medline: 11771811 ]

51. Tafarodi R, Swann W. Two-dimensional self-esteem: theory and measurement. Pers Individ Dif 2001 Oct;31(5):653-673. [doi: 10.1016/s0191-8869(00)00169-0]

52. Hysing M, Harvey A, Stormark K, Pallesen S, Sivertsen B. Precursors of delayed sleep phase in adolescence: a population-based longitudinal study. Sleep 2018 Nov 01;41(11):1-7. [doi: 10.1093/sleep/zsy163] [Medline: 30203021]

53. NCSS. PASS 16 Power Analysis and Sample Size Software. URL: https://www.ncss.com/software/pass/ [accessed 2021-10-15]

54. Bandelow B, Michaelis S. Epidemiology of anxiety disorders in the 21st century. Dialogues Clin Neurosci 2015 Sep;17(3):327-335 [FREE Full text] [Medline: 26487813]

55. Bodden D, Stikkelbroek Y, Dirksen C. Societal burden of adolescent depression, an overview and cost-of-illness study. J Affect Disord 2018 Dec 01;241:256-262. [doi: 10.1016/j.jad.2018.06.015] [Medline: $\underline{30138810]}$

\title{
Abbreviations \\ CATS: Child and Adolescent Trauma Screen \\ NSD: Norwegian Centre for Research Data \\ SDQ: Strengths and Difficulties Questionnaire \\ UiT: The Arctic University of Norway \\ WHO-5: WHO-Five Well-being Index
}

\author{
Edited by G Eysenbach; submitted 06.07.21; peer-reviewed by J Zlamal, A Teles; comments to author 09.09.21; revised version \\ received 23.09.21; accepted 23.09.21; published 08.11.21 \\ Please cite as: \\ Kaiser S, Martinussen M, Adolfsen F, Breivik K, Kyrrestad H \\ An App-Based Intervention for Adolescents Exposed to Cyberbullying in Norway: Protocol for a Randomized Controlled Trial \\ JMIR Res Protoc 2021;10(11):e31789 \\ URL: https://www.researchprotocols.org/2021/11/e31789 \\ doi: $10.2196 / 31789$ \\ PMID:
}

(CSabine Kaiser, Monica Martinussen, Frode Adolfsen, Kyrre Breivik, Henriette Kyrrestad. Originally published in JMIR Research Protocols (https://www.researchprotocols.org), 08.11.2021. This is an open-access article distributed under the terms of the Creative Commons Attribution License (https://creativecommons.org/licenses/by/4.0/), which permits unrestricted use, distribution, and reproduction in any medium, provided the original work, first published in JMIR Research Protocols, is properly cited. The complete bibliographic information, a link to the original publication on https://www.researchprotocols.org, as well as this copyright and license information must be included. 